\title{
Membrane Inlet-based Portable Time-of-flight Mass Spectrometer for Analysis of Air Samples
}

\author{
Tae-Kyu Kim, Kyung-Hoon Jung, Seung-Kyo Yoo, and Kwang-Woo Jung ${ }^{4 *^{*}}$ \\ Department of Chemistry, Koreat A hanced Institute of Science and Technologn, Daeduk Science Town, Daejeon 305-701, Korea \\ Withtech, Inc, Woonij-dong 104-15, Iusung-gu, Daejeon 305-380, Korea \\ -Department of Chemistry and Institute of Basic Science, Wonkuang Lniversitw, Iksan, Chonbuk 570-749, Korea \\ ${ }^{*}$-mail: hwjthg!a wonkwang.ackr \\ Received November 10, 2004
}

\begin{abstract}
A miniaturized time-of-flight mass spectrometer with an electron impact ionization source and sheet membrane introduction has been developed. The advantages and features of this mass spectrometer include high sensitivity. simple structure. low cost compact volume with field portability. and ease of operation. A mass resolution of 400 at $m z 78$ has been obtained with a $25 \mathrm{~cm}$ flight path length. Under optimized conditions. the detection limits for the volatile organic compounds (VOCs) studied were $0.2-10 \mathrm{ppm}$ by volume with linear dy namic ranges greater than three orders of magnitude. The response times for various VOCs using a silicone membrane of $127 \mu \mathrm{m}$ thickness were in the range $4.5-20 \mathrm{~s}$. which provides a sample analysis time of less than 1 minute. These results indicate that the membrane introduction/time-of-flight mass spectrometer will be useful for a wide range of field applications. particularly for environmental monitoring.
\end{abstract}

Key Words : Time-of-flight mass spectrometer, Membrane introduction. VOCs, Real-time analysis

\section{Introduction}

Miniature and field-portable mass spectrometers have played a prominent role in a variety of in situ analysis applications. including environmental analysis. process monitoring. forensics. space applications. and chemical and biological agent detection. ${ }^{1-3}$ Because of their high chemical specificity and exquisite sensitivity. molecular weights and structural information are both available through the appropriate choice of ionization methodology, which means they provide unambiguous identification of sample components. The mass spectrometer of choice is generally a quadrupole device..$^{4-6}$ an ion trap. ${ }^{7-5}$ or less frequently a magnetic sector instrument. ${ }^{10}$ The teclunique of time-offlight mass spectrometry (TOFMS) has also attracted much attention because of its potential for use in numerous fieldportable and remote sampling applications. TOFMS has the advantages over scanning technologies of unlimited mass range. simple design. and rapid delivery of full mass spectra. ${ }^{11-14}$ and thus looks promising for realization of these goals. A transportable TOFMS with a converging annular geometry and an electron impact (EI) source has recently been designed for environmental monitoring of VOCs. ${ }^{15}$ The mass resolution of this instrument is 270 at $m z 91$ (toluene). with a dynamic range of over 10000 . Cornish and Cotter have also developed a miniature TOFMS that uses laser desorption and ionization for biological detection. ${ }^{16}$

The major difficulty encountered in the use of mass spectrometry for the detection and identification of pollutants in the atmosphere arises in the introduction of the sample from atmospheric pressure to the high vacuum of the ion source. Direct expansion of the air into the vacuum chamber of the instrument can be employed and has the advantage that the sampling is relatively unbiased with respect to the molecular properties of the sample constituents. ${ }^{17.18}$ However, an appreciable quantity of air and water vapor are also then admitted. An improvement in the sensitivity of a MS can be achieved by using the selective permeation of certain semipermeable membranes to effectively concentrate the volatile organic samples with respect to the permanent atmospheric gases.

Recent work on membrane introduction mass spectrometry (MIMS) has shown that it is one of the simplest. most efficient. and most sensitive tecluniques for the purpose of on-line or on-site analysis of VOCs and other analytes present in air and water matrices. ${ }^{10-26}$ The principle of the MIMS technique lies in the fact that volatile and semivolatile organic compounds have been found to selectively permeate through hydrophobic membranes such as polydimethylsiloxane (PDMS). also known as silicone. much more quickly than water and other polar substances. ${ }^{27}$ Such a membrane also functions as an efficient interface between the matrix and the high vacuum of the mass spectrometer. The VOCs migrate from the environmental sample to the membrane. concentrate in and diffuse through the membrane. and evaporate from the membrane surface directly into the high vacuum ion source region of the mass spectrometer, in which they are ionized and detected. normally at trace levels.

The first applications of MIMS to air analysis were reported in the early 1970 s. ${ }^{28.29}$ but little attention to realtime monitoring of environmental samples was paid until the $1990 \mathrm{~s}$. The purpose of this paper is to describe experiments with a membrane inlet for direct air sampling coupled to a TOFMS for the analy sis of VOCs. The characteristics of the present sysstem that differentiate it from existing technolo- 
gies are the use of a simple membrane interface into the miniaturized linear type TOFMS without the need for preconcentration steps, a rapid analysis cycle, and a simple geometry that is easy to operate. Detection limits and response times for representative substances have been detemined. Direct comparisons are made between the performance of a conventional direct sample inlet and membrane introduction by fitting both to a TOF.MS. The compactness of the time-of-flight analyzer and of the nocessary ancillary cejuipmonl makes il suilable for constructing a mobile membrane inlet mass spectrometer for onsite processing and real-time environmental andysis.

\section{Experimental Section}

Time-of-Flight Mass Spectrometer. A schemalic diagram of the miniature MI-TOF.MS is shown in Figure 1. It consists of a TOF analyzer (25 cm flight path), mounted on a 4.5 in. cube, the sample inlet system, the electron impact ionizer, and the electronics for the ion source and for data accuisition. Vacum is maintained in this system with a turbomolecular pump (Varian Turbo-V70,70 $\mathrm{J} / \mathrm{s} \mathrm{N}_{2}$ ) backed by a $40 \mathrm{~L} / \mathrm{min}$ mechanical pump. The system unit has dimensions of $50 \times 40 \times 30 \mathrm{~cm}^{3}$, not including the mechanical pump. The pressure in the mass spectrometer with the membrane introduction intertace in place is $\leq 1.3 \times$ $10^{-6}$ Tor. The linear double-stage TOF.MS is based on the Wilcy-Mclaren conliguration ${ }^{3 i}$ and is operated with a pulsed acceleration ficld.

Electrons for ionizing the sample gas in the source region are produced continuously by an electrically heated tungsten filament mounted on a ceramic basc. The elcetron beam is focused by a pietce element and a single lens into the ion source through an $\mathrm{I} \times 10 \mathrm{~mm}^{2}$ aperture. Jons are created by electron bombardment at $70 \mathrm{cV}$. The ionization region is maintained field free during the ionization by applying a constant potential $(1000 \mathrm{~V})$ to the repelling and cxtracting electrodes. Triggered by the start signal, the resulting ions are then extracted toward the detector by applying a $150 \mathrm{~V}$ negative-going pulse to the extracting electrode, which was chosen in order to optimize the space focusing condition. The extracting electrode is pulsed by means of HV push-pull MOSFET switch (Behlke Electronic GmbH, HTS2I-03GS.M) with a rise time of less than 20 ns. Ions are detected with a chevron microchanncl plate detector. The ion signal is fed directly into a transient digitizer (National Instruments. PCl-51 12), which is programmed for automated data acpuisilion and signal averaging. The mass spectra were recorded with a repetition rate of $50 \mathrm{~Hz}$.

Because the ions are all accelerated to the same energy, the velocity of each ion will depend upon its mass to charge ratio. Hence the flight time of the ion also depends on this ratio. One of the main advantages of this technique is that a complete spectrum is gencrated each cycle. Thus the relative intensities of ions in the source are accurately represented. even if source conditions change during the experiment. This is in contrast to scanning spectrometers such as quadrupole, ion trap, and magnetic sector type devices. Additionally, TOF.MS has outstanding transmission, and due to their simple selup are very robust and insensitive to vibrations, which is particularly important for field applications.

Membrane Interface. Two sample introduction modes for introducing chemical vapors and air samples into the mass spectrometer were used in this work for system testing. The first method used an ellusive molecular beam inlet with an adjustable leak valve to introduce the desired gascous sample into the ion source. This configuration does not deliberately concentrate any compounds. The advantages of using a capillary inlet for gascous sample introduction include very fast response times (of the order of seconds). simplicity and ruggedness, and suitability for long-term monitoring experiments.

In the second sampling mode, a membrane inlet system was attached to the opposite side of the electron impact jonizer. The basis of this technique is the selective transport

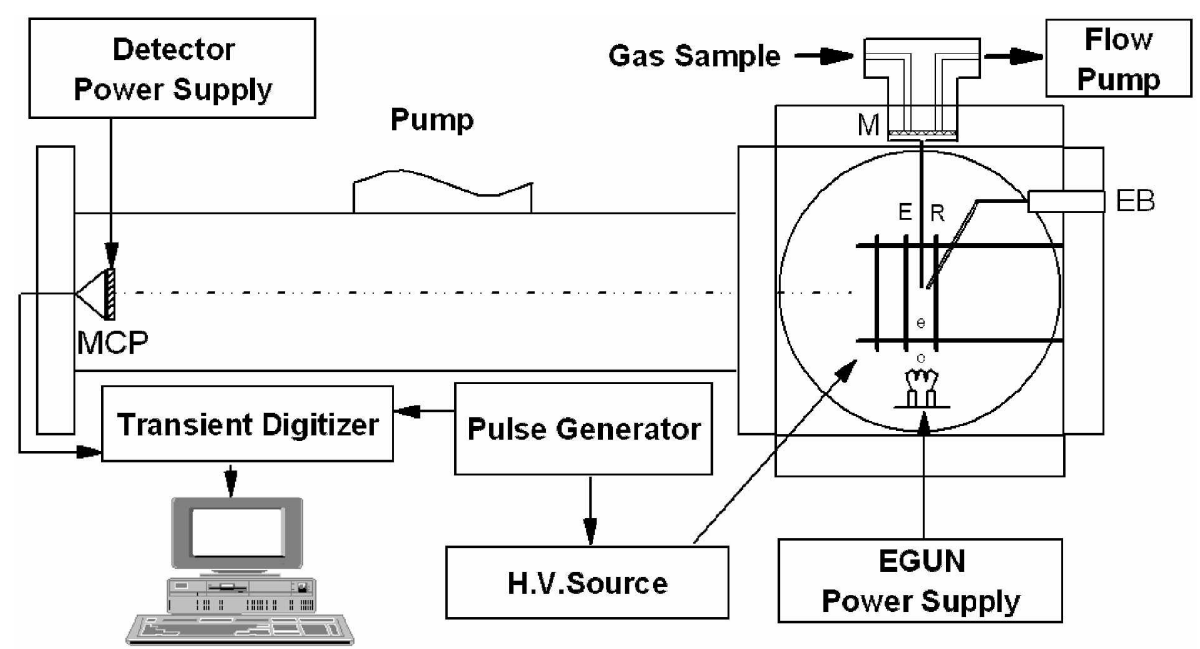

Figure 1. Schematic view of the time-of-llight analyzer-based membrane inlet mass spectrometer: EB, ellusive beam; E. extracting electrode; $R$, repelling electrode; $M$, membrane; MCP, microchannel plate. 
of analy te molccules across a semiperneable membrane into the ion source of the mass spectrometer. The analyte stream flows over a sheet of membrane material, which is usually a silicone rubber. The analyte is adsorbed onto the membrane material and diffises through the membrane along a concentration gradient towards the mass spectrometer inlet. This combination of adsorption and diffusion means that the permeation coefficient depends on the compound and the membrane material. In particular, the pemmeation coefficients of nitrogen and oxygen in silicone membranes are very low compared with, for example, those of small organic molecules. The difference between the permeation rates leads 10 an cnricloment eflect, which allows trace analysis of the VOCs in air samples.

A circular silicone sheet (Dow Coming Corp.. Midland, MI, USA) membranc will a thickness of $127 \mu \mathrm{m}$ is positioned between two machined duralumin blocks and sealed with Viton o-rings (Figure 1). The effective membrane arca is $12.6 \mathrm{~mm}^{2}$. This arca provides an acceplable compromise between sensitivity and the amount of air admitted into the vacuum chamber. The membrane interface is connected by a Swagelock union to a 0.0625 in. o.d. $\times 0.021$ in. i.d. transfer tube, which is inserted 2 in. into the center of the TOFMS ion source to ensure a maximum density of analyte molecules in the ionization region. Air llow over the membrane was regulated by means of a small air sampling pump placed at the sample outlet of the membrane assembly. The pumping speed can be varied up to $300 \mathrm{~mL} / \mathrm{min}$, and the pump was powered with a regular $9 \mathrm{~V}$ battery.

Gaseous standards for the VOCs were made using a home-builı gas calibration device at a concentration range of $0.1-10^{4}$ ppm for mass calibration and external quanlification. Room air, passed through a water trap, was used to supply the sample dilution system. All of the chemicals (analytical grade, Aldrich Chenical) for system (esling and calibration were used as received without futther purification.

\section{Results and Discussion}

Figure 2 shows the TOF mass spectrum obtained for the effusive beam inlet sampling of benzene vapor $\left(\mathrm{P}_{\text {stmpl }}-2.0\right.$ $\times 10^{-6}$ Torr) at $70 \mathrm{eV}$ impact energy. This spectrum was averaged over 500 pulses taking a data point every 4 ns. The mass spectrum clearly shows the parent ion $(m=78)$ at 7.43 $\mu s$ and the air components corresponding to $\mathrm{N}_{2}(m=28)$ and $\mathrm{O}_{2}(m \geq 32)$ at $4.57 \mu \mathrm{s}$ and $4.86 \mu \mathrm{s}$ respectively. The peak width at hal irheight can be used 10 estimate the resolution of the mass spectrometer. The peak width for the $\mathrm{C}_{6} \mathrm{H}_{t}$, ion represents $9.25 \mathrm{~ns}$ FWH.M. The resolution is defined as $R=$ $T 2 \Delta T$, where $T$ is the total Hight time of the ion packet and $\Delta \%$ is the FWHM of the peak. In this case the resolution is 400 at 78 amu, indicating that this instrument is adecuate for the analysis of the majority of VOCs in air samples.

As described in the experimental section, two methods for introducing chemical vapors into the mass spectrometer were used in this work. In order to understand the elfects of these sample introduction methods on detection sensitivity,

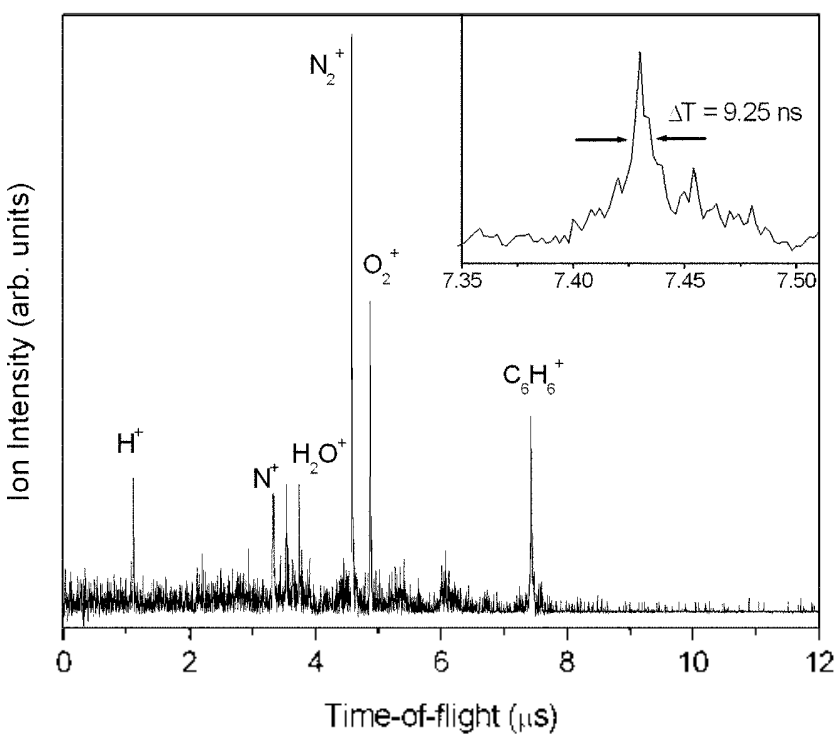

Fignre 2 Typical $70 \mathrm{eV}$ electron impact time-of-flight mass spectrum of a bencene sample using the effusive beam inlet method. The spectrum is averaged for 500 shots at 4 ns per channel.

mass spectra were obtained for a benzene sample. Figure 3 a shows the background spectrum of ambient air obtained with the MI-TOFMS. Most of the ion peaks at lower $m z$ values result from air and water vapors that have permeated litrough the membranc. The $\mathrm{O}_{2}$ and $\mathrm{N}_{2}$ peaks observed in each spectum can be used for mass calibration; hence no external standards are needed during air sampling. When the sample consisting of $1600 \mathrm{ppm}$ benzenc in air was introduced by effusive beam (Figure 3b), no significant difference between the mass spectrom and the background spectrum was detected. However, in the membrane introduction

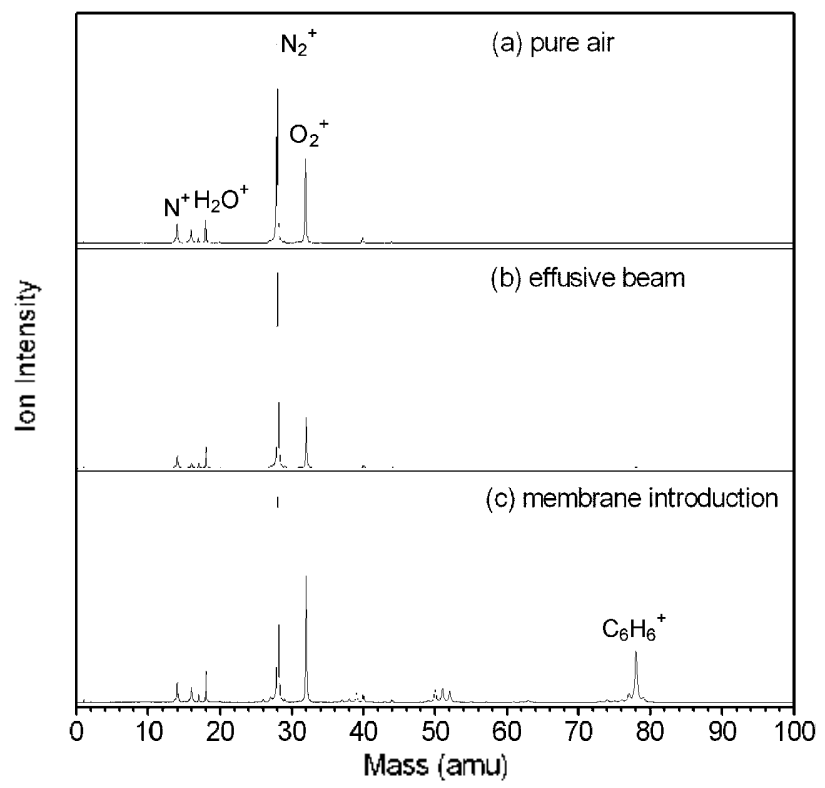

Figure 3. Comparison of MI-TOF mass spectra of (a) background, (b) $1600 \mathrm{ppm}$ benzene in air using the effusive beam inlet, and (c) $1600 \mathrm{ppm}$ benzene in air using membrane introduction. 
mode, a very distinct feature appears, as shown in Figure $3 \mathrm{c}$. The benzene sample produces several significant peaks of $\mathrm{C}_{3} \mathrm{H}_{3}(m=39), \mathrm{C}_{1} \mathrm{H}_{2}(m=50), \mathrm{C}_{1} \mathrm{H}_{3}(m=51), \mathrm{C}_{1} \mathrm{H}_{1}(m z$ $52)$, and $\mathrm{C}_{6} \mathrm{H}_{6},(m=78)$ ions; the most significant peak is that of $\mathrm{C}_{6} \mathrm{H}_{6}$ ion. This result demonstrates that the higher solubility of benzene molecules in the silicone membrane than of inorganic air components leads to the enrichment of the benzene concentration after sample permeation through the membrane. The advantage of membrane introduction is thus more sensitive delection by the TOFMS instrument, compared with the effusive beam inlet under similar conditions, which indicates membrane introduction should be used in environmental air sampling.

For identification of each analyte in actual samples, mass discrimination between the observed ions in the full mass spectrum is desired. In order to test the system wilh a multicomponent sample, a mixture of volatile organic analytes was prepared, containing chlorobenzene, 1,2-dichlorocllane, o-xylenc, each at $500 \mathrm{ppm}$ in air. A membrane introduction TOF mass spectrum of this mixture is shown in Figure 4, which is in good agreement with the $70 \mathrm{eV}$ clectron impact mass spectrum of each component from the NIST Standard Reference Database. ${ }^{31}$ For example, $o$-xylene (denoted as . 1) produces distinct ions with $m=91$ and $m z$ 106, corresponding to $\mathrm{C}_{7} \mathrm{H}_{7}$ and $\mathrm{C}_{8} \mathrm{H}_{11}$ respectively. The presence of the chlorobenzene (denoted as (") component can also be confimed from its parent ion with $m \geq 112$, whereas 1,2-dichloroethane (denoled as $D$ ) produces a characteristic ion fragment $\mathrm{C}_{2} \mathrm{H}_{3} \mathrm{Cl}(m=62)$. These results demonstrate that the MI-TOF-MS can be used in qualitative analysis of air samples.

To measure the detection limits and linearity ranges of the different inlet configurations, samples with various concentrations of toluenc vapor in air were examined. This

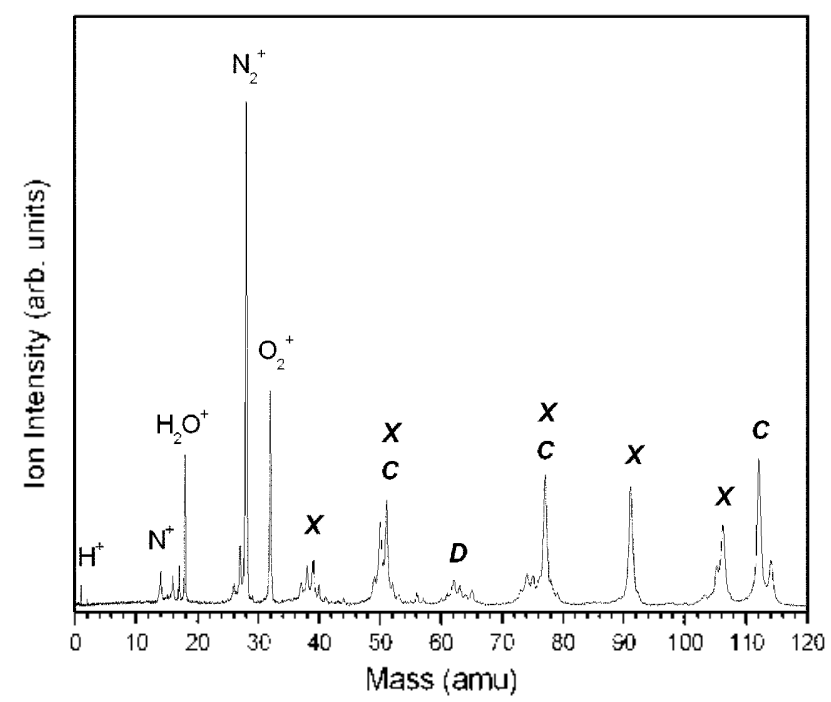

Figure 4. Metnbrane introduction time-of-flight mass spectrum of a sample containing $500 \mathrm{ppm}$ of each of chlorobenzene (denoted as ( ) 1,2-dichloroethane (denoted as $D$ ), and (2-xylene (denoted as $\lambda$ ) in air. The flow rate of the sample was $300 \mathrm{ml}$ min. Pressure in the vacuum chamber was below $5,10^{-6}$ Torr.

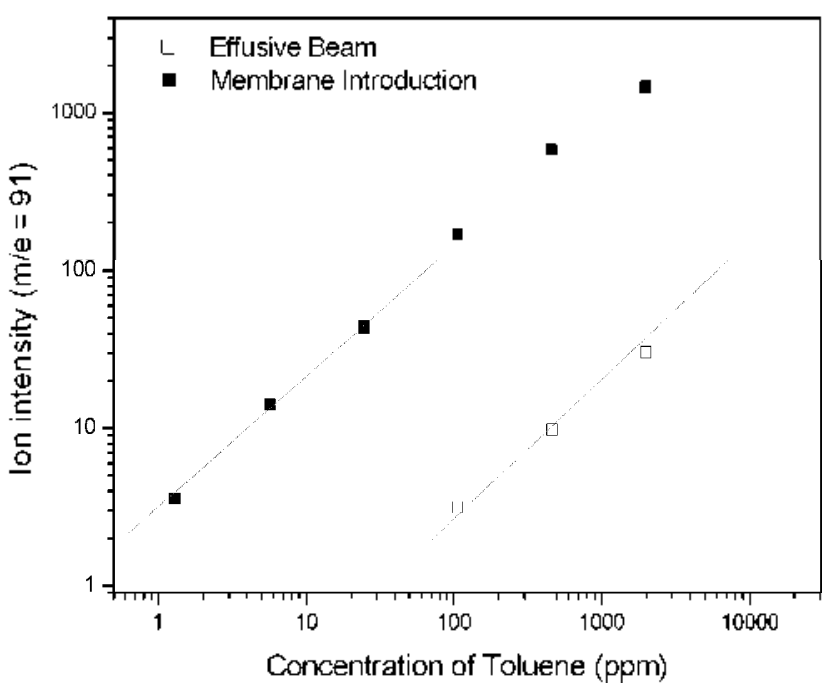

Figure 5. Calibration curves for toluene in air. $\boldsymbol{\square}$, membrane introduction (concentration range $1-2000 \mathrm{ppm}$ ); I , effusive beam inlet (concentration range $100-9000 \mathrm{ppm}$ ). The high selectivity of the silicone membrane results in a detection limit of $0.2 \mathrm{ppm}$ versus $35 \mathrm{ppm}$ for the effusive beam inlet.

comparison allows us to estimate the sensitivity obtainable using a membrane inlet. Figure 5 shows the relationship between the sample concentration and the signal intensity of the $(\mathrm{M}-\mathrm{H})$ ion $(m=91)$ for each mass spectrum. The upper plot shows the results for toluene concentrations from 1 to $2000 \mathrm{ppm}$ in air, using membrane inlroduction. The data points fall approximately on a straight line and indicate reasonable linearity and instrument stability. The lower plot shows the results for toluene concentrations from 100 to $9000 \mathrm{ppm}$ in air, obtained using the eflusive beam inlet. The lower limit for detecting toluene was reduced from $35 \mathrm{ppm}$ for the effusive beam inlet $100.2 \mathrm{ppm}$ wilh membranc introduction. The detection limits of this instrument can be further improved by increasing the electron impact current and the detector sensitivity. This result implies that membrane introduction significanlly enhances sensitivity over that of the effusive beam inlet by two orders of magnitude. If this also holds for other chemical species, it would be possible to detect ppb levels of atmospheric gases with a membrane introduction time-of-flight mass spectrometer. As can be seen in Figure 5, the linear dynamic range of the membrane introduction method extends well beyond 3 orders of magnitude. These wide dynamic ranges are in good agreement with the dynamic ranges measured for other VOCs in carlier studics. ${ }^{32.3 .3 .1}$

In order to determine the basic membrane parameters, the time dependence of the signal from the mass spectrometer was investigated. The sample modulation was controlled with an alternating valve that switches between the sample stream and the background stream. Typical time versus signal intensity profiles for introduction with a $127, \mathrm{~mm}$ membrane are shown in Figure 6 along with the temporal responses for methanol, benzene, toluene, and $o$-xylene. The time dependence of the ion intensity for each analyte was obtained from the gate integration of the largest peak in the 


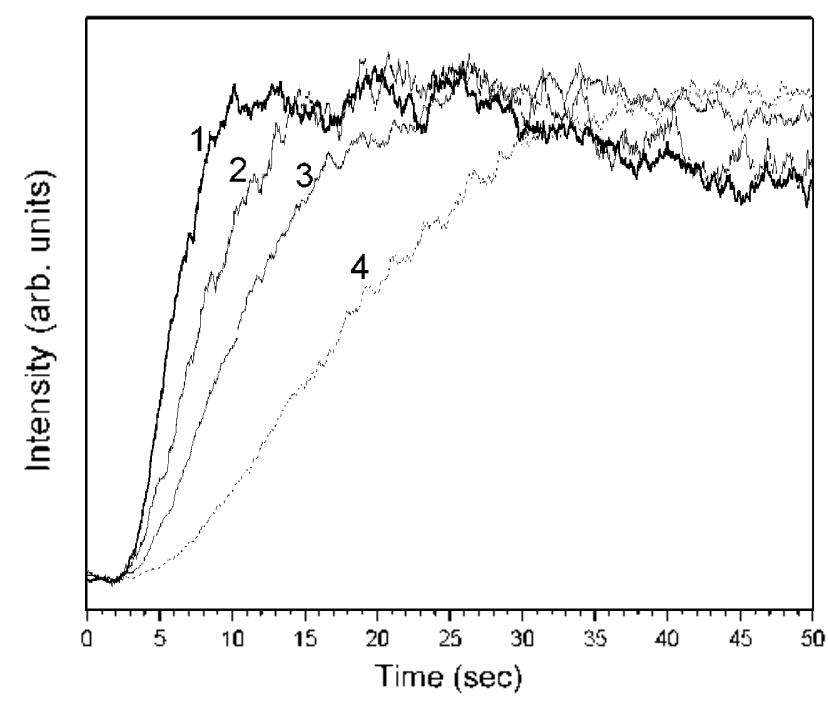

Figure 6. Response time measurements for four different analytes obtained with a $127 / \mathrm{mm}$ membrane: 1 , methanol; 2 , benzene; 3 , toluene; 4, $\theta-x y l e n e$. The time dependence of each ion intensity was obtaned from the gate integration of the largest peak in the TOF mass spectrum of each analyte, ie., methanol $(m=31)$, benzene $(m z-78)$, toluene $(m z 91)$. and $\theta-x y k n e(m z 91)$. The signal interisities have been normalized to facilitate the comparison.

time-of-flight mass spectrum of cach sample. The response time is the time taken for the signal intensity to rise from 10 to $90 \%$ of its maximum value:

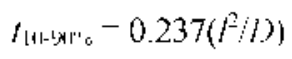

where $/$ and $l$ ) are the membrane thickness and the diffusion coeflicient respectively. ${ }^{3+}$ From this equation it can be seen that the response time is inversely proportional to the diffusion coefficient. The signal increases rapidly after a short lag period and then apparently levels off. The measured response times varied considerably for different substances and were in the range $4.5-20 \mathrm{~s}$. This observation is consistent with the findings of Ketola and coworkers ${ }^{\text {i. }}$ that the response times of various VOCs range from 12 to $27 \mathrm{~s}$ for a $100 \mu \mathrm{mm}$ silicone sheet membrane. The aronatic compounds of benzene ( $9 \mathrm{~s})$, toluene (15 s), and $\theta$-xylene $(20 \mathrm{~s})$ resulted in slower responses than methanol molecule (4.5 s), primarily due to their molecular size. The rapid response times obtained for VOCs indicate that rapid concentration changes in the environmental air sample can easily be monitored by the MI-TOF.MS method. This is also very important for the rapid detemnination of VOCs at trace levels in air samples.

Detection limits, linear dynamic ranges and response times for the various VOCs are summarized in Table 1 . The decection limits for most compounds are low, especially for aromatic compounds which have detection limits at the sub ppm level. The more polar compounds have higher detection limils, as expecled because of the hydrophobic nature of the silicone membrane ${ }^{35}$ For example, acetone has a detection limit of $4.2 \mathrm{ppm}$ and iodomethane has a detection limit of $9.8 \mathrm{ppm}$ at room temperalure. higher than those of benzene, toluene, and $o$-xylene. The noise limiting the sensitivity was
Table 1. Estimated detection limits, response times and dytramic ranges for selected volatile compounds

\begin{tabular}{lccc}
\hline Compounds & $\begin{array}{c}\text { limit of } \\
\text { Detection } \\
(\mathrm{ppm})\end{array}$ & $\begin{array}{c}\text { Respotse } \\
\text { Time (s) }\end{array}$ & $\begin{array}{c}\text { I incar Dynamic } \\
\text { Range } \\
\text { (ppm) }\end{array}$ \\
\hline benzene & 0.5 & 9 & $4.5-1600$ \\
toluenc & 0.3 & 15 & $1.3-2000$ \\
o-xylene & 0.4 & 20 & $2.0-700$ \\
chlorobenzene & 0.1 & 15 & $0.5-700$ \\
1,2-dichloroethane & 0.6 & 8 & $3.4-1200$ \\
acctone & 4.2 & 10 & $40-3700$ \\
iodomethane & 9.8 & 7 & $80-28000$ \\
\hline
\end{tabular}

mostly due to fluctuations in the background rather than to instrumental noise. so detection limits better than those shown in Table 1 should be achicvable with a cleaner vacuum system and improved ion collection efficiency. The linear dynamic ranges were over three orders of magnitude. which are even wider than the linear dynamic ranges of effusive beam sample introduction.

\section{Conclusion}

We have shown in this study that volatile organic substances in air can be analyzed with a miniature membranc introduction/(ime-of-flight mass analyzer with a good resolution ( 400 at $m z 78$ ) and sensitivity that is comparable to those of conventional full-sized TOF instruments. The detection limits for the volatile organic compounds studied were in the range $0.2-10 \mathrm{ppm}$ with linear dynamic ranges geater than three orders of magnitude. The major advanlages of the MI-TOFMS system are its small instrumental volume, simple geometry, and ease of operation, especially when pumps of minimum size are used. The whole system is casily portable and its maintenance is simple and rapid. In addition. this mass spectrometer provides fast responses. whereas conventional analytical methods always require the use of sample enrichment processes before measurement. The use of more efficient ionization such as laser ionization should yield a significant reduction in the sample concentration required to achieve the same signal intensity. Therefore, the MI-TOFMS can be used for long-term continuous monitoring of environmental, biological and chemical processes.

Acknowledgment. This work was supported by Wonkwang Universily in 2003.

\section{References}

I. Allen, T. M.; Falconer, T. M.: Cisper, M. E.: Borgerding, A. J.; Wilkerson, C. W. Jr. Anal. (hem. 2001, 73, 4830.

2. Bocchini, I': I'ozzi, R.: Andalo, C.; Galletti, G C. Anal. ('hem 2001, 73, 3824 
3. Ketola. R. A.: Kiuru. J. T.: Tarkiainen. V.: Kotiaho. T.: Sysoev. A. A. Rapid Contmin. Hass Spectrom 2003. 17. 753.

4. Orient. O. J.: Chutiian. A.: Garkanian. V. Rev. Sci. Instrmm. 1997. $68,1393$.

5. Ferran, R. I. Boumsellek. P. S. J. Tac. Sci. Technol 1996. IH. 1258 .

6. Short. R. T.: Fries. D. P.: Toler. S. K.: Lembke. C. E.: Byrne. R. H. Meas. Sci. Technol. 1999.10.1195.

7. Tabert. A. M: Griep-Raming. J.: Guymon. A. J.: Cooks. R. G. Anal. Chem. 2003. 75. 5656 .

8. Lister A. K.: Wood K. V.: Cooks. R. G.: Noon. K. R. Bionedical and Emmommental Mass Spectrometry 1989,18, 1063.

9. Moxom. J.: Reilly. P. T. A.: Whitten. W. B.: Ramsey. J. M. Anal. Chem. 2003. 75.3739.

10. Sinha. M. P.: Tomassian. A. D. Rev: Sci. Instrtme 1991. 62. 2618

11. Badman, E. R: Cooks, R. G. J. Mass Spectrom. 2000. 35, 659 .

12. Henry. C. And. Chem. Wews Features Ap. 1. 1999 264A.

13. Seo, Y. C.: Kim. K. D; Kim. N. I. Bull. Konem Chem. Soc, 2002. 23.432 .

14. Song. K.: Cha. H.: Kim. D.: Min. K. Bull. Korean Chem. Soc. 2004. 25.101

15. White, A. I.: Blanire, M. G.: Corlett. C. A.: Griffths, B. W.: Martin. D. M: Spencer, S. B. Mullock; S. I. Rev. Sci. Ifstrum. 1998, 69, 565 .

16. Comish. T. J.: Cotter. R. J. Anal. Chem. 1997. 69.4615

17. Heger. H. J.: Zimmermann. R.: Dorfher. R.: Beckmann. M.: Griebel. H.: Kettrup. A.: Boesl. U. Anal. Chem. 1999. 71.46

18. Mulhlberger, F.: Zimmermanil. R.: Kettrup, A. Afhal. Chem. 2001. 73,3590 .

19. Allen. T. M.: Cisper M. E.: Hemberger. P. H.: Wilkerson, C. W.
Int. J. Hass Sipectrom. 2001. 212. 197

20. Ketola. R. A.: Kotiaho. T.: Cisper. M. E.: Allen. I. M. J. Mass Spectront. 2002.37. 457.

21. Allen, T. M.: Falconer, T. M: Cisper. M. E:- Borgerding. A. J.; Wilderson. C. W. Anal. Chem. 2001. 73. 4830 .

22. Bocchini, P.: Pozzi, R.: Andalo, C.: Galletti, G. C. Anal Chem. 2001. 73.3824

23. Riter. L. S.: Takats. Z.: Cooks. R. G. Anahst 2001. 126. 1980.

24. Riter. L. S.: Takats. Z.: Charles. L.: Cooks. R. G. Rapid Conmum Mass Spectrom. 2001. 15. 1520.

25. Alberici, R. M: Sparrapan, R: Jardim, W. F; Eberlin. M. N Environ. Sci. Techol. 2001.35. 2084.

26. Alberici. R. M:: Zampronic. C. G.: Poppi. R. T.: Eberlin. M. N. Anahys 2002. 127. 230 .

27. Johnson. R. C.: Cooks. R. G.: Allen. T. M: Cisper. M. E.: Hemberger. P. H. Mass Spectrom. Rev 2000, 19, 1

28. Collins, G. G.; Utley, D. Chem Industoy 1972, 15.84.

29. Westover, L. B.: Tou, J. C.: Mark, J. H. Anal Chem 1974. 46. 568.

30. Wiley. W. C.: McLaren. I. H. Ren: Sci. Instrim. 1955. 26. 1150.

31. NIST Standard Reference Database 69: November 1998 Release NIST Chemistry WebBook:

32. Cisper. M. E; Gill. C. G: Tounsend, L. E.; Hemberger. P. H Anal. Chem. $1995,67.1413$.

33. Ketola. R. A.: Ojala. M.: Sorsa. H.: Kotiaho. T.: Kostiainen. R Anal. Chim. Acta 1997.319.359

34. Overney. F. L.: Enke. C. G. J. An. Soc. Mass Spectron. 1996. 7. 93

35. Kotiaho, T.: Lauritsen. F. R.: Choudhury, T. K.: Cooks, R. G.; Tou. J. C.: Westover. L. B. Anal Chem 1991. 63,875A. 